\title{
The craniofacial anthropometric measurement in a population of normal newborns of Kolkata
}

\author{
Ghosh $A,{ }^{1 *}$ Manjari $C,{ }^{2}$ Mahapatra $S^{3}$ \\ ${ }^{1}$ Department of Anatomy, North Bengal Medical College \& Hospital, Darjeeling, W.B, India, ${ }^{2}$ Dept. of Anatomy, \\ Medical College, Kolkata, W.B., India, ${ }^{3}$ Dept. of Pediatrics, N.R.S. Medical College, Kolkata, W.B., India
}

* Corresponding Author:

Dr. Anasuya Ghosh,

Asst. Prof., Dept. of Anatomy,

North Bengal Medical College,

P.O.- Sushrutanagar, Dist- Darjeeling, West Bengal, India

E-mail: dr_anasuyaghosh@live.com

\section{Citation}

Ghosh A, Manjari C, Mahapatra S. The craniofacial anthropometric measurement in a population of normal newborns of Kolkata. Nepal Journal of Medical sciences 2013;2(2):125-9.

\begin{abstract}
Background: The anthropometric measurement of the craniofacial region plays an important role in the evaluation of the newborn with dysmorphic features and their corrective surgery. This study was undertaken to establish a baseline craniofacial dataset for the newborn population of Kolkata where it is still lacking.

Methods: In this study, we obtained the measurement of 6 distinct parameters (length of nose, height of nose, width of columella, length of philtrum, width of philtrum, oral commissural distance) of craniofacial region of 1860 healthy newborns (both male \& female). Their body weight was recorded. We compared the values in both sexes and also in normal \& low birth weight babies.
\end{abstract}

Results: Our study shows statistically significant higher values in all parameters except oral commissural distance among male than female newborn. It again results statistically significant higher values of length of nose, length of philtrum and oral commissural distance in normal birth weight newborns than the low birth weight group in both sexes.

Conclusion: We here present a set of reference value for the newborn population (both normal \& low birth weight) of East India (Kolkata).

Keywords: anthropometry; craniofacial; newborn; sexual dimorphism

\section{Background:}

Anthropometry (Greek, literally meaning "measurement of humans") refers to the measurement of the human individual for the purpose of understanding human physical variation. The face is involved in many syndromes of dysmorphogenesis. ${ }^{1}$ To treat congenital or post-traumatic facial disfigurements in members of these groups successfully, surgeons require access to craniofacial databases based on accurate anthropometric measurements. Normative data of facial measurements are indispensable for precise determi- nation of the degree of deviations from the normal. ${ }^{2}$ There is importance of anthropometric indices of head and face in forensic medicine, surgery, pediatrics and medical imaging techniques. The philtrum of the upper lip has a unique configuration and is a landmark of individual distinction. Since it is frequently involved in disfiguring oro-facial malformations, it is important that a thorough understanding of its anatomical relationships be established so that functional and aesthetic surgical corrections can be accomplished. ${ }^{1}$ Anthropometric measurements of the nose may help to answer 
important clinical questions in research on the effects of surgery on nasal and facial development. ${ }^{3}$

\section{Methods:}

The study was an observational; hospital based cross sectional study; performed at R.G. Kar Medical College and Hospital, Kolkata, India and was conducted from Jan., 2009-August 2009 and again from Sept, 2011 to Dec, 2011. The parents of the babies belonged to Kolkata and nearby areas of West Bengal, so the ethnic origin of the babies was Bengali.

Measurements were taken of 6 distinct parameters of craniofacial region of 1860 healthy newborns (both male and female) and body weight was recorded. Values were compared in both sexes and also in normal and low birth weight babies.

The babies with following criteria were included in the study sample only:

i) The full term (37-40 weeks of gestation), healthy babies born by any means

ii) The babies devoid of any gross congenital anomalies

iii). Babies without any history of birth asphyxia, any form of distress or illness

iv) Babies without maternal history of Diabetes Mellitus, Hypertension, cardiac and renal diseases.

Total 1571 babies were included in this study. The babies were divided into 4 groups according to their sex and birth weight for easier comparison and description, they are:

1. Normal birth weight (NBW) male

2. Normal birth weight (NBW) female

3. Low birth weight (LBW) male

4. Low birth weight (LBW) female

In the study population, normal birth weight newborns (male 530, female 530) were total 1060 and low birth weight (male 400, female 400) newborns were 800 in numbers.

Parameters for the study are as follows-

1. Length of nose -Nasion to a point at tip of the nose in line with the upper edge of both nostrils. ${ }^{4}$

2. Height of nose- Distance from base of columella to a point at tip of nose in line with the upper edge of both nostrils. $^{4}$
3. Width of columella -Measured at middle portion of columella with a caliper. ${ }^{4}$

4. Length of philtrum- From the base of columella to the midline depression of vermillion border. ${ }^{4}$

5. Width of philtrum- Two points were marked at the base of the philtrum; at junction of vertical ridge of philtrum and vermillion border of upper lip. The width between these points was taken as the philtral width. ${ }^{5}$

6. Length of oral commissure- distance between the corners of mouth. ${ }^{6}$

7. Birth weight - recorded from the corresponding history sheet (hospital bed ticket) of the newborns.

By international agreement low birth weight has been defined as a birth weight of less than $2.5 \mathrm{~kg}$ (up to and including $2499 \mathrm{gm}$ ), the measurement being taken preferably within first hour of life, before significant postnatal weight loss has occurred. ${ }^{7}$ A LBW infant is any infant with a birth weight of less than $2.5 \mathrm{~kg}$ regardless of gestational age. ${ }^{8}$ Body weight of the babies were collected as per available in hospital records as ideally the newborn body weight should be recorded within first hour of life. ${ }^{9}$

This study was performed after proper approval by the Ethics committee and with prior written consent of parents of the babies. All the measurements were taken in presence of a resident pediatrician during day time from $2 \mathrm{pm}$ to $4 \mathrm{pm}$ on weekdays when the cases were asleep. It was done to avoid variation due to facial expression.

The measurement was delayed for 24 hours after birth to allow facial swelling and distortions to recede. Every measurement was taken twice by the same examiner and recorded in the corresponding form. A third reading was taken if the initial two measurements showed a large discrepancy, and the two closer readings would then be used. The head circumference was measured using a non- stretchable measuring tape in centimeters. The remaining parameters were measured by spreading calipersand digital calipers taking into account the error if any, in the instruments. All the values were tabulated, compared and analyzed by using Epical 2000 v1.02 statistical software.

\section{Results:}

Total 1860 newborns were selected for study. Among them the number of normal birth weight (NBW) male and female was 530 each and low birth weight (LBW) male and LBW female was 400 each. The average birth weight of male newborns with NBW is $2.75 \mathrm{~kg}$ where as it is $2.9 \mathrm{~kg}$ in 
case of normal female newborn. In case of LBW male and female newborns the average weight is $2.15 \mathrm{~kg}$ and $2.16 \mathrm{~kg}$ respectively. We have obtained the measurements of the normal nose length, height of nose, length and width of philtrum, width of collumella, and oral commissural distance in normal and low birth weight newborn population of Kolkata. All the values have been analyzed statistically and tabulated. All the measurements are given in centimeters.

In table 1 and 2, the mean and standard deviation of all parameters in normal and low birth weight babies of both sexes have been plotted. In addition, the values have been compared for any statistically significant difference.

Table 1: Gender wise comparison of various parameters of normal birth weight children

\begin{tabular}{|c|c|c|c|c|c|c|}
\hline \multirow[t]{2}{*}{ Parameters } & \multicolumn{2}{|c|}{$\begin{array}{l}\text { Male (NBW) } \\
\text { in } \mathrm{cm} .\end{array}$} & \multicolumn{2}{|c|}{$\begin{array}{c}\text { Female } \\
(\mathrm{NBW}) \text { in } \mathrm{cm})\end{array}$} & \multirow{2}{*}{ 兰 } & \multirow{2}{*}{ 总 } \\
\hline & Mean & S.D. & Mean & S.D. & & \\
\hline Nose length & 1.53 & 0.11 & 1.5 & 0.14 & 3.88 & 0.00 \\
\hline Height of nose & 0.73 & 0.09 & 0.69 & 0.07 & 8.08 & 0.00 \\
\hline Width of collumella & 0.29 & 0.05 & 0.27 & 0.06 & 5.09 & 0.00 \\
\hline Length of philtrum & 0.79 & 0.09 & 0.7 & 0.14 & 12.45 & 0.00 \\
\hline Width of philtrum & 0.52 & 0.07 & 0.5 & 0.08 & 4.33 & 0.00 \\
\hline $\begin{array}{l}\text { Oral commissural } \\
\text { distance }\end{array}$ & 2.15 & 0.15 & 2.14 & 0.13 & 1.16 & 0.25 \\
\hline
\end{tabular}

Table- 2: Gender wise comparison of various parameters of low birth weight children

\begin{tabular}{|c|c|c|c|c|c|c|}
\hline \multirow[t]{2}{*}{ Parameters } & \multicolumn{2}{|c|}{$\begin{array}{c}\text { Male (LBW) } \\
\text { in } \mathrm{cm}\end{array}$} & \multicolumn{2}{|c|}{$\begin{array}{c}\text { Female (LBW) } \\
\text { in cm }\end{array}$} & \multirow{2}{*}{ 总 } & \multirow{2}{*}{ 兰 } \\
\hline & Mean & S.D. & Mean & S.D. & & \\
\hline Nose length & 1.45 & 0.12 & 1.38 & 0.13 & 7.91 & 0.00 \\
\hline Height of nose & 0.73 & 0.09 & 0.69 & 0.09 & 6.29 & 0.00 \\
\hline Width of collumella & 0.28 & 0.13 & 0.23 & 0.04 & 7.35 & 0.00 \\
\hline Length of philtrum & 0.73 & 0.17 & 0.67 & 0.15 & 5.29 & 0.00 \\
\hline Width of philtrum & 0.38 & 0.15 & 0.5 & 0.1 & 3.33 & 0.00 \\
\hline $\begin{array}{l}\text { Oral commissural } \\
\text { distance }\end{array}$ & 2.1 & 0.14 & 2.09 & 0.25 & 0.7 & 0.49 \\
\hline
\end{tabular}

From table 1, it is clear that, the NBW male has statistically highly significantly higher values in all parameters than NBW females except oral commissural distance.

Similarly, Table 2 shows that, LBW male babies again have statistically highly significantly higher values in all but the oral commissural distance than the LBW females.

In table 3 and 4 , the values of NBW males and females have been compared with their LBW counterparts. The NBW male newborns have statistically significantly higher values in nose length, length and width of philtrum and oral commissural distance than the LBW male newborns (Table 3).

Table 3: Comparison of various parameters in male children of different birth weights

\begin{tabular}{|c|c|c|c|c|c|c|}
\hline \multirow[t]{2}{*}{ Parameters } & \multicolumn{2}{|c|}{$\begin{array}{c}\text { Male(NBW) } \\
\text { in cm. } \\
(\mathrm{n}=530)\end{array}$} & \multicolumn{2}{|c|}{$\begin{array}{l}\text { Male (LBW) } \\
\text { in cm., } \\
(\mathrm{n}=400)\end{array}$} & \multirow[t]{2}{*}{ 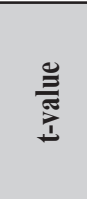 } & \multirow[t]{2}{*}{ 兰 } \\
\hline & Mean & S.D. & Mean & S.D. & & \\
\hline Nose length & 1.53 & 0.11 & 1.45 & 0.12 & 10.56 & 0 \\
\hline Height of nose & 0.73 & 0.09 & 0.73 & 0.09 & 0.00 & 1 \\
\hline Width of collumella & 0.29 & 0.05 & 0.28 & 0.13 & 1.62 & 0.11 \\
\hline Length of philtrum & 0.79 & 0.09 & 0.73 & 0.17 & 6.94 & 0.00 \\
\hline Width of philtrum & 0.52 & 0.07 & 0.38 & 0.15 & 18.93 & 0.00 \\
\hline $\begin{array}{l}\text { Oral commissural } \\
\text { distance }\end{array}$ & 2.15 & 0.15 & 2.1 & 0.14 & 5.18 & 0.00 \\
\hline
\end{tabular}

The NBW females have statistically significant higher values in nose length, length of philtrum, width of collumella and oral commissural distance only (Table 4) than their LBW counterpart.

Table 4: Comparison of various parameters in female children of different birth weights

\begin{tabular}{|c|c|c|c|c|c|c|}
\hline \multirow[t]{2}{*}{ Parameters } & \multicolumn{2}{|c|}{$\begin{array}{c}\text { Female (NBW) } \\
\text { in } \mathrm{cm} . \mathrm{n}=530\end{array}$} & \multicolumn{2}{|c|}{$\begin{array}{c}\text { Female } \\
(\mathrm{LBW}) \text { in } \mathrm{cm} . \\
\mathrm{n}=400\end{array}$} & \multirow[t]{2}{*}{ 兰 } & \multirow[t]{2}{*}{ 总 } \\
\hline & Mean & S.D. & Mean & S.D. & & \\
\hline Nose length & 1.5 & 0.14 & 1.38 & 0.13 & 13.34 & 0.00 \\
\hline Height of nose & 0.69 & 0.07 & 0.69 & 0.09 & 0.00 & 1 \\
\hline Width of collumella & 0.27 & 0.06 & 0.23 & 0.04 & 11.52 & 0.00 \\
\hline Length of philtrum & 0.7 & 0.14 & 0.67 & 0.15 & 3.14 & 0.002 \\
\hline Width of philtrum & 0.5 & 0.08 & 0.5 & 0.1 & 0.00 & 1 \\
\hline $\begin{array}{l}\text { Oral commissural } \\
\text { distance }\end{array}$ & 2.14 & 0.13 & 2.09 & 0.25 & 3.95 & 0.00 \\
\hline
\end{tabular}

So, our study shows significant sexual dimorphism in most of the facial anthropometric parameters among NBW newborn population where the males have statistically significant higher values. This pattern of sexual dimorphism 
has also been observed in LBW newborn group where the values were again higher for male babies.

\section{Discussion:}

India is a land of diversity and people of different provinces have different food habit, life style, socio-cultural trend and ethnicity. The diversity is evident in their physical structure and anthropometric parameters.

The present study was conducted to obtain a baseline standard criterion of lip-nose complex of East Indian (Kolkata) population. The values for North Indian population are marginally different from this set of values. ${ }^{1}$ Both these studies have one similar finding that a statistically significant sexual dimorphism observed in philtral length in healthy newborns with normal birth weight. In comparison to another study in Chinese babies width of columella at mid point showed similar value whereas other parameters showed no similarity. ${ }^{10}$

In a study of nose and upper lip region on neonates of Western part of India shows higher values in philtral length in both normal male and female newborns, but the average values for males are higher than female neonates. ${ }^{11}$ It supports our study finding.

The oral commissural length is almost similar among neonates of Western and Eastern parts of India. It is $21.5 \mathrm{~mm}$ and $21.5 \mathrm{~mm}$ for Eastern Indian male and female newborn of normal birth weight whereas the mean value for oral commissural length in male and female neonates for Western part of India is 23.6 and $22.1 \mathrm{~mm}$ respectively. But these values are quite higher in case of Caucasians $(33 \mathrm{~mm}$ and $35 \mathrm{~mm}$ ), Chinese (33 $\mathrm{mm}$ and $34 \mathrm{~mm}$ ) and Black (35 and $38 \mathrm{~mm}$ ) neonates. ${ }^{11-13}$ In a study at Pondicherry (1991), two hundred term healthy neonates were examined and 14 anthropometric measurements were taken in the face and ear region. Difference between the sexes was observed in ear length, ear breadth, and philtrum. ${ }^{14}$ It also supports our findings in case length of philtrum. Study of these age related morphological variations within the nose and upper lip region is not available for Indians. For years together the anthropometric measurements for surgical reconstructions are based on basic values for western population resulting in the time of surgical repair being based on western growth patterns, which actually differs for Indians. ${ }^{11}$ The human body dimensions are affected by ecological, biological, geographical, racial, gender and age factors and for this reason every population group should have their definite anthropometric data set for future reference. ${ }^{15}$ In different countries all over the world, even at different parts of India, various teams of scientists have been gathering the data of different craniofacial parameters for future reference. This study is a small initiative for preparing a reference data set for the newborn population of Eastern part of India and to provide a ready database to the clinicians.

Conclusion: We here present a set of reference value for the newborn population (both normal and low birth weight) of East India (Kolkata).

\section{Acknowledgements:}

We are really thankful to all the doctors and non-medical staffs of the Nursery ward, Dept. of Pediatrics, R.G.Kar Medical College and Hospital for their co-operation for performance of the study.

\section{References:}

1. Agnihotri G, Singh D. Craniofacial Anthropometry in Newborns and Infants. Iran J Pediatr 2007;17:332-8.

2. Farkas LG, Katic MJ, Forrest CR, et al. International anthropometric study of facial morphology in various ethnic groups/races. J Craniofac Surg 2005;16:615-46.

3. Doddi NM, Eccles R .The role of anthropometric measurements in nasal surgery and research: a systematic review. Clin Otolaryngol 2010;35:277-83.

4. Shah M, Verma IC, Mahadevan S, et al. Facial anthropometry in newborns in Pondicherry. Indian J Pediatr 1991;58:259-63.

5. Singh S, Bhalla LR, Khanna VK. Relationship between width of maxillary central incisors and width of philtrum. J India Den Asso 1971;43:264-9.

6. Franz ML, SokolA. B. The proportioned philtrum: a helpful measurement and ratio. Cleft Palate J 1972;43:143-6.

7. WHO. Nutrition in preventive medicine, WHO monograph; Geneva, 1976;62: 567.

8. K.Park. Preventive and Social Medicine, 2000; 18:395.

9. Bailar JC III, Meyer EA, Pool R, et al. Assessment of the NIOSH Head-and-Face Anthropometric Survey of U.S. Respirator Users. Washington DC: The National Academic Press, 2007:29.

10. Cho BC, Kim JY, Yang JD, et al. Anthropometric study of the upper lip and nose of infants less than a year of age. J Craniofac Surg 2006;17:57-61.

11. Khandekar B, Srinivasan S, Mokal N, et al. Anthropo- 
Original Article | Ghosh A, et al. Craniofacial anthropometric measurement

metric analysis of lip-nose complex in Indian population. Indian J Plastic Surg 2005;38:128-31.

12. Farkas LG, Cheung GCK. Nostril asymmetry: Microform of cleft lip palate? An anthropometrical study of healthy North American Caucasians. Cleft Palate J 1979;16:351-7.

13. Farkas LG, Hajnis K, Posnick JC. Anthropometric and anthroscopic findings of the nasal and facial region in cleft patients before and after primary lip and palate repair. Cleft Palate Craniofac J 1993;30:1-12.

14. Shah M, Verma IC, Mahadevan S, et al. Facial anthropometry in newborns in Pondicherry. Indian J Pediatr 1991;58:259-63.

15. Mibodi IMA, Farahani MR. Study of normal range of anatomical dimensions of one-day old newborn by cephalometry. J Med Counc Islamic Repub Iran 1996;14:1-8. 